\title{
PROJECT REPORT
}

Ensuring contact: calling rural Appalachian older adults during the COVID-19 epidemic

\section{AUTHORS}

Robert B Walker ${ }^{1}$ MD, MS, Professor of Family Medicine

Michael Grome ${ }^{2}$ BS, PA-C, Assistant Professor of Family and Community Health

William Rollyson ${ }^{3}$ MD, Research Coordinator

Adam D Baus ${ }^{4}$ PhD, MA, MPH, Research Assistant Professor; Director *

\section{CORRESPONDENCE}

*Prof Adam D Baus abaus@hsc.wvu.edu

\section{AFFILIATIONS}

1, 2, 3 Marshall Health, Marshall University, 1600 Medical Center Drive, Huntington, WV 25701, USA

${ }^{4}$ West Virginia University School of Public Health, Department of Social and Behavioral Sciences - Office of Health Services Research, 64 Medical Center Drive, Morgantown, WV 26506, USA

\section{PUBLISHED}

18 January 2021 Volume 21 Issue 1

HISTORY

RECEIVED: 24 May 2020

REVISED: 17 November 2020

ACCEPTED: 22 November 2020

\section{CITATION}

Walker RB, Grome M, Rollyson W, Baus AD. Ensuring contact: calling rural Appalachian older adults during the COVID-19 epidemic. Rural and Remote Health 2021; 21: 6122. https://doi.org/10.22605/RRH6122

This work is licensed under a Creative Commons Attribution 4.0 International Licence

\section{ABSTRACT:}

Introduction: Older adults, especially those aged 85 years or older, remain at significantly higher risk for COVID-19. This group, along with those with pre-existing heart and lung disease and diabetes, have accounted for $80 \%$ of hospitalizations and an even higher percentage of COVID-19 related deaths in the USA. West Virginia, the only state in the USA located completely within Appalachia, has a higher percentage of elderly than all but two states in the nation. Rural seniors are hesitant to use hospital emergency departments and attend routine care visits for fear of exposure to the virus. Restricted cell phone and internet service may limit effective technological outreach to more isolated rural older adults. More information is needed to develop effective, safe, and acceptable approaches to care for rural, isolated older adults.

Methods: Telephone interviews were conducted with 124 community-dwelling residents in four counties in rural Appalachia between 1 and 22 April 2020. Participants were aged 75 years or 
older. Descriptive statistics were calculated and Fisher's Exact Test was used to examine for associations among variables.

Results: Participants consisted of 86 (69.4\%) women and 38 (30.6\%) men with an average age of 82.5 years. Telephone contact was the preferred method of contact among all but four participants (96.8\%). Seventeen calls (13.7\%) resulted in some form of intervention, including arranging for emergent home repairs, treatment of severe hypertension, scheduling urgent laboratory testing, arranging for terminal care, treating acute conditions, and providing durable medical equipment. The 17 participants requiring intervention were significantly more likely to be aged 85 years or older $(p=0.004)$, and report two or more chronic Keywords:

Appalachia, geriatrics, patient assessment, qualitative research, USA. conditions $(p<0.001)$. Those describing themselves as 'lonely' were significantly more likely to live alone $(p=0.009)$ and describe themselves as 'anxious' or 'depressed' ( $p<0.001)$.

Conclusion: A telephone call appears to be the most effective means of communication with patients in these rural Appalachian counties. Patients aged 85 years or older and those living alone should be given highest priority for regular outreach by healthcare providers. In this population, systematically calling rural elderly patients during the COVID-19 epidemic and its aftermath represents an effective strategy for providers who care for elderly rural patients.

\section{FULL ARTICLE:}

\section{Introduction}

The world has changed for older adults living in rural Appalachia during the COVID-19 pandemic. While younger and healthier patients tend to be positioned to return to work and school, older adults, especially those aged 85 years or more, remain at significantly higher risk when returning to social activities ${ }^{\mathbf{1 , 2}}$. This group, along with those with pre-existing heart and lung disease and diabetes, have accounted for $80 \%$ of hospitalizations and an even higher percentage of COVID-19 related deaths in the USA ${ }^{3}$. Even before the pandemic, there was substantial evidence of health disparities between older Americans living in rural areas and their urban and suburban counterparts. These disparities include access to care, income, quality of life, and adverse health outcomes $\mathbf{1}^{\mathbf{1}, \mathbf{4}, \mathbf{5}}$. West Virginia, the only US state located completely within Appalachia, has a higher percentage of elderly than all but two states in the nation ${ }^{\mathbf{6}}$. Rural seniors rely on community health centers, the rare local private provider, and local health departments for their health care. They are hesitant to use hospital emergency departments and attend routine care visits for fear of exposure to the virus ${ }^{\mathbf{7}}$. Restricted cell phone and internet service may limit effective technological outreach to more isolated rural older adults. More information is needed to develop effective, safe, and acceptable approaches to care for rural older adults who are currently isolating at home and will be in relative isolation for the duration of the pandemic.

\section{Methods}

Telephone interviews were conducted with older adults, aged 75 years or older, living in rural areas of four counties in southwestern West Virginia (Cabell, Lincoln, Putnam, and Wayne counties), to estimate access to communication, food, supplies, and medicine, areas of greatest concern, the most acceptable and effective methods of communication, and the need for acute intervention. All or parts of these counties are designated as Health Professional Shortage and Medically Underserved Areas by the Health Resources and Services Administration. One hundred and twenty-four people were contacted for interview, with all individuals agreeing to take part. Participants were active, established patients age 75 years or older and receiving care at a rural community health center and an academic geriatric health center emphasizing rural health, with the exclusion of zip codes that include urban and suburban areas. Participants were actively living within the community and were not living in a residential facility. The interviews were conducted by three health providers actively providing care at the two organizations. Participants were informed that the interviewing providers were checking on them and trying to determine the best way to communicate with others like them, and that their information would be documented and analyzed but their identity would be kept strictly confidential. Participants were not billed for this communication. Interviews were conversational but elicited specific information as well as open-ended comments about greatest concerns and immediate needs. Descriptive statistics were calculated and Fisher's exact test was used to examine for associations among variables.

\section{Ethics approval}

This research was approved by the Marshall University Medical Institutional Review Board (IRBNet ID\# 1590308-1).

\section{Results}

\section{Demographic characteristics}

One hundred and twenty-four telephone interviews were conducted between 1 and 22 April 2020. No patient contacted refused to provide an interview. Participants consisted of 86 (69.4\%) women and 38 (30.6\%) men with an average age of 82.5 years. Thirty-nine participants (31.5\%) were 85 years of age or older. Thirty-eight participants (30.6\%) reported that they lived alone, 57 (46.0\%) lived with a spouse, and 29 (23.4\%) lived with others, usually relatives.

\section{Health profile}

Twenty-eight participants (22.6\%) described themselves as 'lonely', $32(25.8 \%)$ as 'anxious or nervous', 21 (16.9\%) as 'depressed', and $38(30.6 \%)$ reported both anxiety and depression. Troublesome hearing loss was reported by more than half $(64,51.6 \%)$ of participants but rarely $(7,5.6 \%)$ was it a serious barrier to communication. Forty-five participants (36.3\%) reported two or 
more chronic conditions and 27 (21.8\%) reported 3 or more. Diabetes mellitus was reported by 37 participants (29.8\%), heart disease by 51 (41.1\%), and hypertension by 89 (71.8\%). All older adults contacted stated that they had reasonable access to supplies, food, and medicine.

\section{Communication and use of technology}

Telephone contact was the preferred method of contact among all but four participants (96.8\%). Ninety participants (72.6) stated that cell phone service was available where they lived, and

71 participants (57.3\%) had a cell phone. Those without cell phone service were significantly more likely to be aged 85 years or older $(p<0.001)$ and to live alone $(p<0.001)$. Seventy-seven participants (62.1\%) stated that they had access to internet service, 53 (42.7\%) reported that there was an internet-enabled device (such as a smartphone, tablet or laptop computer) in the home, but only $37(29.8 \%)$ stated that they could use it.

\section{Social distancing}

All but four participants (96.8\%) stated that they were practicing some degree of social isolation, although the majority $(65,52.4 \%)$ reported that three or more people entered and left the home on a daily basis. Everyone interviewed stated that they were actively socializing during the pandemic in various ways: 111 (89.5\%) stated they used the telephone to socialize; 38 (30.6\%) used the internet; 112 (90.3\%) stated that they socialized face-to-face in some way.

\section{Intervening}

Seventeen calls (13.7\%) resulted in some form of intervention - in addition to medication refills. These included arranging for emergent home repairs, treatment of severe hypertension, scheduling urgent laboratory testing, arranging for terminal care, treating acute conditions, and providing durable medical equipment. The 17 participants requiring intervention based on the call were significantly more likely to be aged 85 years or older $(p=0.004)$, and to report two or more chronic medical conditions $(p<0.001)$. Those describing themselves as 'lonely' were significantly more likely to live alone $(p=0.009)$ and describe themselves as 'anxious' or 'depressed' $(p<0.001)$.

\section{Discussion}

This study found that a telephone call is arguably the most effective means of communication in the central highlands of Appalachia, including West Virginia. Use of telephone outreach is especially important in the midst of COVID-19, as nearly $90 \%$ of those surveyed noted use of the telephone to socialize. According to US Census data, about $98.5 \%$ of owned or renter-occupied West Virginia households have telephone service ${ }^{\mathbf{8}}$, although cellular telephone service and internet access remain much more limited, as demonstrated by the more than $40 \%$ of participants in these interviews who reported lack of access to one or the other.
Telemedicine is evolving quickly and has been found to be useful in disaster situations $\mathbf{9 - 1 1}^{\mathbf{1 1}}$. Telephone contact with health providers has been shown to be acceptable to patients and is comparable to the more expensive video-conference ${ }^{\mathbf{1 2}, 13}$. A single call from a health provider will often identify those in greatest need. The calls placed were well received by the participants. At the least, these calls confirm a linkage with the patient, help to reduce loneliness and isolation, and provide an opportunity to underscore important recommendations and guidelines ${ }^{\mathbf{1 0}}$. At best, these calls can identify correctable problems, with $13.7 \%$ of calls resulting in an intervention. This study attributes the response rate to the preexisting, close-knit connections between the healthcare providers and patients of these two rural health systems. Leveraging simple telephone outreach to rural older adults should not be discredited, even as health interventions in the US continue to become increasingly digital.

Older adults appear to be at increased risk for COVID-19, in terms of contracting the disease and developing severe illness. Those aged 85 years or more are at even higher risk for COVID-19 $1,14$. Rural older adults may be especially vulnerable because, even before the pandemic, disparities existed in access to care and adverse health outcomes compared to national, non-rural counterparts. As society begins to reduce social isolation, staying home may continue to be recommended for older adults, especially those of more advanced age and with chronic health conditions. Alternative methods to provide home-based care are needed for these patients. Developing and implementing such methods will require information about acceptable, effective, and efficient ways to link with rural older adults.

Resources at rural community health centers and other practices are limited. Establishing priorities for calling is important. Based on these interviews, patients aged 85 years or more, those living alone, and those with two or more chronic medical conditions should be given highest priority. In this population, systematically calling rural elderly patients during the COVID-19 epidemic and its aftermath represents an effective strategy for providers who care for elderly rural patients and have the capacity to do so.

\section{Conclusion}

This study aimed to estimate the availability of food, supplies, and medicine, areas of greatest concern, the most acceptable and effective methods of communication, and the need for acute intervention for older adults aged 75 years or older and living in rural central Appalachia during the COVID-19 pandemic. A telephone call appears to be the most effective means of communication with patients in these rural Appalachian counties. Patients aged 85 years or more and those living alone should be given highest priority for regular outreach by a healthcare provider. In this population, systematically calling rural elderly patients during the COVID-19 epidemic and its aftermath represents an effective strategy for providers who care for elderly rural patients. 
1 Henning-Smith C. The unique impact of COVID-19 on older adults in rural areas. Journal of Aging \& Social Policy 2020; 32(4-5): 396-402. DOI link, PMid:32475255

2 Davoodi N, Healy M, Goldberg E. Rural America's hospitals are not prepared to protect older adults from a surge in COVID-19 cases. Gerontology and Geriatric Medicine 2020; (7 July): 2333721420936168. DOI link, PMid:32685610

3 Centers for Disease Control and Prevention COVID-19 Response Team. Severe outcomes among patients with coronavirus disease 2019 (COVID-19) - United States, February 12 - March 16, 2020. Morbidity and Mortality Weekly Report 2020; 69(12): 343. DOI link, PMid:32214079

4 Lasser KE, Himmelstein DU, Woolhandler S. Access to care, health status, and health disparities in the United States and Canada: results of a cross-national population-based survey. American Journal of Public Health 2006; 96(7): 1300-1307. DOI link, PMid:16735628

5 Bolin JN, Bellamy GR, Ferdinand AO, Vuong AM, Kash BA, Schulze A, et al. Rural Healthy People 2020: new decade, same challenges. Journal of Rural Health 2015; 31(3): 326-333. DOI link, PMid:25953431

6 Goldberg TH, Saul B. The aging population of the USA and West Virginia - the demographic imperative. West Virginia Medical Journal 2016; 112(3): 32-34.

7 Rosenbaum L. The untold toll - the pandemic's effects on patients without COVID-19. New England Journal of Medicine 2020; 10.1056/NEJMms2009984. DOI link, PMid:32302076
8 United States Census Bureau, American Community Survey. Tenure by telephone service available by age of householder. Available: web link (Accessed 30 December 2020).

9 Nicole N, Carr BG. The role of telehealth in the medical response to disasters. Journal of the American Medical Association Internal Medicine 2018; 178(6): 745-746. DOI link, PMid:29710200

10 Lindsay J, Hogan J, Ecker A, Day S, Chen A, Helm A. The importance of video visits in the time of COVID-19. The Journal of Rural Health 2020; 37(1): 242-245. DOI link, PMid:32506751

11 Woodall T, Ramage M, LaBruyere J, McLean W, Tak C. Telemedicine services during COVID-19: considerations for medically underserved populations. The Journal of Rural Health 2020; 231-234. DOI link, PMid:32613657

12 Delichatsios H, Callahan M, Charlson M. Outcomes of telephone medical care. Journal of General Internal Medicine 1998; 13(9): 579-585. DOI link, PMid:9754512

13 Rush KL, Howlett L, Munro A, Burton L. Videoconference compared to telephone in healthcare delivery: a systematic review. International Journal of Medical Informatics 2018; 118: 44-53. DOI link, PMid:30153920

14 Wu Z, McGoogan JM. Characteristics of and important lessons from the Coronavirus Disease 2019 (COVID-19) outbreak in China: summary of a report of 72314 cases from the Chinese Center for Disease Control and Prevention. Journal of the American Medical Association 2020; 10.1001/jama.2020.2648. DOI link, PMid:32091533

This PDF has been produced for your convenience. Always refer to the live site https://www.rrh.org.au/journal/article/6122 for the Version of Record. 